BMJ Paediatrics Open

\section{Psychological health in preschool children with underweight, overweight or obesity: a regional cohort study}

To cite: Donkor HM, Toxe H, Hurum J, et al. Psychological health in preschool children with underweight, overweight or obesity: a regional cohort study. BMJ Paediatrics Open 2021;5:e000881. doi:10.1136/ bmjpo-2020-000881

- Additional material is published online only. To view, please visit the journal online (http://dx.doi.org/10.1136/ bmjpo-2020-000881).

Received 17 September 2020 Revised 12 February 2021 Accepted 15 February 2021

Check for updates

(c) Author(s) (or their employer(s)) 2021. Re-use permitted under CC BY-NC. No commercial re-use. See rights and permissions. Published by BMJ.

For numbered affiliations see end of article.

Correspondence to Dr Trond Markestad; Trond. Markestad@uib.no

\section{ABSTRACT}

Objective To examine if underweight (UW), overweight (OW) or obesity (OB), or body mass index (BMI) expressed as its SD score (BMI SDS), were associated with psychological difficulties in preschool children.

Design Regional cohort study.

Setting Oppland County, Norway.

Methods At the routine school entry health assessment at 5-6 years of age, parents were invited to participate by local public health nurses. The parents completed questionnaires on sociodemographic, health and lifestyle factors of the child and the family, and on the child's neurocognitive development. They assessed psychological health with the Strengths and Difficulties Questionnaire (SDQ). Public health nurses measured weight and height on all eligible children and reported age, sex, height and weight anonymously for the children who declined to participate.

Participants We obtained information on 1088 of 1895 (57\%) eligible children. The proportion of UW, OW and OB was slightly higher among the children who declined.

Main outcome measures SDQ subscale and Total Difficulties Scores.

Results The mean SDQ scores and proportion of scores zthe 90th percentile had a curvilinear pattern from UW through normal weight (NW), OW and OB with NW as nadir, but the pattern was only significant for the mean Emotional problems, Peer problems and Total SDQ Scales, and for the Total SDQ Score $\geq$ the 90th percentile (TDS90). After adjusting for relevant social, developmental, health and behavioural characteristics, TDS90 was only significantly associated with UW in multiple logistic regression analyses, and only with the lowest quartile of BMI SDS in a linear spline regression analysis.

Conclusions The study suggests that UW and low BMI, but not $\mathrm{OW}, \mathrm{OB}$ or higher $\mathrm{BMI}$, are independent risk factors for having psychological symptoms in preschool children.

\section{INTRODUCTION}

The obesity $(\mathrm{OB})$ epidemic is a major threat to the health of the individual and societies. ${ }^{1}$ The high proportion of children with overweight $(\mathrm{OW})$ or $\mathrm{OB}$ is particularly worrisome since they are at high risk of $\mathrm{OB}$ as adults. ${ }^{2}$ $\mathrm{We}^{3}$ and others ${ }^{4-7}$ have shown that a variety of well-intended intervention programmes to curtail OB in children have had minor or

\section{What is known about the subject?}

- Underweight, overweight and obesity are associated with psychological symptoms in older children and adolescents.

- The significance of psychological symptoms related to weight has rarely been reported, and with conflicting results, in preschool children.

\section{What this study adds?}

In children aged 5-6 years, obesity and underweight, but not overweight, were significantly associated with psychological symptoms, as assessed with the Strengths and Difficulties Questionnaire.

- After adjusting for social, health and lifestyle factors in the family, only underweight and a low BMl were significantly associated with psychological symptoms

no significant effect. The programmes have generally been oriented towards improving dietary habits and physical activity. Given the limited success, the significance of psychological aspects during early childhood needs to be explored to increase our understanding of why prevention and treatment are so difficult.

$\mathrm{OB}$ is associated with psychological comorbidities, such as depression, low self-esteem and reduced health related quality of life in adults, ${ }^{8}$ older children and adolescents. ${ }^{9-13}$ However, it is not settled whether, or to what extent, psychological factors may predispose to $\mathrm{OW}$ or $\mathrm{OB}$, or simply are a result of having a high body mass index (BMI). Studies are conflicting regarding the significance of attention deficit hyperactivity disorder (ADHD) and other behavioural difficulties as risk factors for OW and OB. ${ }^{14-16}$ Studies on psychological symptoms related to unhealthy weights in young children are scarce, but it has been suggested that neither OW or $\mathrm{OB},{ }^{101718}$ nor underweight (UW) ${ }^{18}$ may be associated with psychological symptoms in 
preschool children. In particular we lack knowledge related to UW. However, UW in this age group has been associated with increased parental concern ${ }^{19}$ and with food avoidant behaviour and an altered parent-child interaction around meals, ${ }^{20}$ which may suggest risks of psychological consequences.

In a regional Norwegian cohort of children aged 5-6 year, we found that OW and OB, but not UW, were associated with unfavourable sociodemographic factors and lifestyles. ${ }^{21}$ The aim of the present paper was to examine if the children with UW, OW or OB in this cohort had more psychological symptoms than the children with a normal weight (NW), or whether psychological symptoms were related to certain BMI scores. Our hypothesis was that children at this age may not have been exposed to significant psychological consequences of their BMI, such as bullying, and that any psychological symptoms associated with weight categories other than NW might be considered risk factors for developing unhealthy weights.

\section{MATERIALS AND METHODS Participants}

Parents of all children entering school in Oppland County, Norway, in 2007, were invited to participate at the routine school entry health assessment at 5-6 years of age. Oppland county had a population of approximately 183000 . The county had two cities with $25000-30000$ inhabitants in each and otherwise rural areas with towns of variable sizes.

Consenting parents completed questionnaires on sociodemographic, health and lifestyle factors of the children and family members, and on neurocognitive development of the children. They assessed their children's psychological health with the Norwegian version of the Strengths and Difficulties Questionnaire (SDQ). ${ }^{22}{ }^{23}$

The public health nurses measured the height and weight of all eligible children. For the families who declined, the nurses reported age, sex, height and weight anonymously. We have previously concluded that the participating children were fairly representative of all the eligible children, although the prevalence of UW, OW and $\mathrm{OB}$ was slightly higher among those who declined. ${ }^{21}$

\section{Patient and public involvement statement}

Public healthcare clinics, but not families, were involved concerning content and design.

\section{Anthropometric measurements, health and habits}

Height and weight were measured according to national guidelines. ${ }^{24}$ BMI was calculated as weight $/$ height $^{2}(\mathrm{~kg} /$ $\mathrm{m}^{2}$ ), and BMI SD scores (BMI SDS) were based on Norwegian references. ${ }^{25}$ Definitions of the weight groups UW, NW, OW and OB were based on the sex and age specific BMI criteria of the International Obesity Task Force for the children ${ }^{26} 27$ and according to the WHO classification for their parents. ${ }^{28}$
Details on sociodemographic factors, health and habits were published in a previous report. ${ }^{21}$ We dichotomised parent's education and the following variables from frequency scores on sets of variables in the questionnaire: nutritional standard, physical activity, physical health related problem, dental caries, difficulties in fine motor, language or social skills or sleep, and behavioural difficulties in the family. Details are presented in online supplemental appendix 1 .

\section{The Strengths and Difficulties Questionnaire (SDQ)}

The SDQ is a screening tool to detect mental health problems in children aged 4-16 years. ${ }^{22}$ The questionnaire consists of 25 items addressing five subscales with five items in each: emotional problems scale, hyperactivity scale, conduct problems scale, peer problems scale and prosocial scale. Each item is scored on a threepoint scale: not true, somewhat true and certainly true, and each scale is scored with a range of $0-10$. For the subscales other than the prosocial scale, higher scores mean more symptoms, and scores at or above the 90th percentile are associated with significant mental health problems. ${ }^{22}$ The prosocial scale is scored opposite to the other subscales, and a score below the 10th percentile may indicate a behaviour problem. A Total Difficulty Score (TDS) is created by summing the scores from the first four subscales (range 0-40), and a TDS at or above the 90th percentile (TDS90) is considered a high risk of having a psychiatric disorder. ${ }^{22}$ On an impact scale, the parents state whether the child has any difficulties with emotions, concentration, behaviour or in social contact with other people, and if so, which impact it has on everyday life (range $0-10$ ).

The SDQ has been formally translated and validated in Norway. ${ }^{23}$ It has been widely used in all the Scandinavian countries, and the distribution of SDQ scores is very similar for comparable age groups within Norway and between the Nordic countries. ${ }^{29}$

\section{Statistics}

Descriptive statistics are presented as counts and per cents (\%) for categorical variables and as means and SD for continuous variables. We explored the differences in characteristics between the four weight groups UW, $\mathrm{NW}$, OW and OB by using one-way analysis of variance (ANOVA) for continuous and the $\chi^{2}$ test for categorical variables. When ANOVA or $\chi^{2}$ tests across all weight groups showed significant differences, we performed post hoc pairwise testing, comparing the other weight groups to NW with the Dunnet's t-test for continuous and the $\chi^{2}$ test for categorical variables (table 1 ).

We tested the significance of the weight groups UW, $\mathrm{OW}$ and $\mathrm{OB}$ as compared with NW, on outcome in terms of TDS90 versus lower TDS scores by logistic regression analyses, both unadjusted and adjusted. We adjusted for variables that differed significantly between groups in the ANOVA or $\chi^{2}$ test analyses, and for variables that we considered relevant from earlier literature and from 
Table 1 Associations between current weight category and the children's personal characteristics, health and habits, and current sociodemographic and health characteristics of parents and siblings (A), and between weight category and scores on the Strengths and Difficulties Questionnaire (SDQ) scales (B). Unselected regional cohort of 5-year-old children in Oppland County, Norway

\begin{tabular}{|c|c|c|c|c|c|}
\hline & $\begin{array}{l}\text { All } \\
(n=1088)\end{array}$ & $\begin{array}{l}\text { Underweight } \\
\text { ( } \mathrm{n}=89)\end{array}$ & $\begin{array}{l}\text { Normal weight } \\
(\mathrm{n}=844)\end{array}$ & $\begin{array}{l}\text { Overweight } \\
(n=117)\end{array}$ & $\begin{array}{l}\text { Obese } \\
(n=38)\end{array}$ \\
\hline
\end{tabular}

\begin{tabular}{|c|c|c|c|c|c|c|c|}
\hline \multicolumn{8}{|l|}{ (A) Characteristics } \\
\hline \multicolumn{8}{|l|}{ Children's health and habits } \\
\hline Age in years, mean (SD) & 1088 & $5.72(0.43)$ & $5.66(0.44)$ & $5.72(0.43)$ & $5.66(0.37)$ & $5.82(0.57)$ & 0.105 \\
\hline Girls, \% & 1088 & 52.5 & 49.4 & 51.8 & 58.1 & 57.9 & 0.487 \\
\hline BMI SDS, mean (SD) & 1085 & $0.01(1.03)$ & $-1.93(0.56) \ddagger$ & $-0.10(0.63)$ & $1.42(0.28) \ddagger$ & $2.36(0.44) \ddagger$ & $<0.001$ \\
\hline $\begin{array}{l}\text { Physical activity poorer than peers§, } \\
\%\end{array}$ & 1073 & 5.1 & 5.6 & 3.8 & $7.9 \ddagger$ & $24.3 \ddagger$ & $<0.001$ \\
\hline Any physical health problemsףl, \% & 1016 & 28.1 & 27.2 & 28.2 & 26.6 & 31.6 & 0.943 \\
\hline Any dental caries-parent report, \% & 1079 & 20 & 19.1 & 18.7 & 25.4 & 34.2 & 0.051 \\
\hline Low nutritional standard ${ }^{\star \star}, \%$ & 1070 & 12.8 & 11.4 & 13.1 & 11.4 & 13.5 & 0.929 \\
\hline Difficulties with skills or sleep†t, \% & 1062 & 29.1 & 28.4 & 29 & 28.2 & 37.1 & 0.76 \\
\hline Kindergarten from 2 years of age, \% & 1033 & 92.1 & 91.6 & 92.7 & 90.7 & 82.4 & 0.163 \\
\hline \multicolumn{8}{|c|}{ Sociodemographic factors and health characteristics of parents and siblings } \\
\hline Municipality $w / n>20000, \%$ & 1087 & 32.4 & 38.2 & 32.6 & 30.8 & 18.4 & 0.178 \\
\hline Low maternal education, \% & 1068 & 44.9 & 44 & 41.6 & $56.9 \ddagger$ & 81.1‡ & $<0.001$ \\
\hline Low paternal education, $\%$ & 1037 & 60.7 & 51.8 & 58.8 & $72.7 \ddagger$ & $85.7 \ddagger$ & $<0.001$ \\
\hline Both parents low education, \% & 1077 & 38.4 & 36.5 & 35.3 & $50.9 \ddagger$ & $73.7 \ddagger$ & $<0.001$ \\
\hline Mother out of work, $\%$ & 1069 & 8.2 & 8.1 & 7.5 & 10.4 & 18.9 & 0.072 \\
\hline Father out of work, \% & 1046 & 4.8 & 4.7 & 3.9 & 7.9 & $15.2 \ddagger$ & 0.009 \\
\hline Parent(s) non-Western, \% & 1088 & 2.7 & 3.4 & 2.1 & 3.4 & $10.5 \ddagger$ & 0.015 \\
\hline Living with one caretaker, \% & 1073 & 13 & 9.3 & 12.1 & 17.2 & $29.7 \ddagger$ & 0.006 \\
\hline No siblings, \% & 1065 & 9.1 & 4.5 & 8.9 & $15.9 \ddagger$ & 2.9 & 0.017 \\
\hline Mother smoking, \% & 1088 & 19 & 14.6 & 16.6 & $31.6 \ddagger$ & $44.7 \ddagger$ & $<0.001$ \\
\hline Current BMI mother, mean (SD) & 981 & $24.32(3.85)$ & $23.03(3.29)$ & $24.07(3.64)$ & $26.09(4.20) \ddagger$ & $27.52(5.12) \ddagger$ & $<0.001$ \\
\hline Current BMI father, mean (SD) & 924 & $26.38(3.30)$ & $25.09(2.71) \ddagger$ & $26.26(3.16)$ & $27.54(3.71) \ddagger$ & $28.89(4.33) \ddagger$ & $<0.001$ \\
\hline BMI SDS average for siblings & 630 & $-0.21(1.23)$ & $-0.79(1.24) \ddagger$ & $-0.23(1.20)$ & $0.25(1.06) \ddagger$ & $0.55(1.45) \ddagger$ & $<0.001$ \\
\hline Mother currently obese, \% & 980 & 9.1 & 6.2 & 7.1 & $17.5 \ddagger$ & $34.3 \ddagger$ & $<0.001$ \\
\hline Father currently obese, $\%$ & 924 & 13 & $3.8 \ddagger$ & 11.3 & $25.5 \ddagger$ & $37.5 \ddagger$ & $<0.001$ \\
\hline Both parents currently obese, $\%$ & 891 & 2.7 & 1.3 & 2 & 3.3 & $19.4 \ddagger$ & $<0.001$ \\
\hline Behaviour difficulties in family, \% & 1088 & 6.2 & 3.4 & 5.3 & $10.3 \ddagger$ & $18.4 \ddagger$ & 0.001 \\
\hline \multicolumn{8}{|l|}{ (B) SDQ item } \\
\hline Emotional problems scale, mean (SD) & 1059 & $1.16(1.43)$ & $1.48(1.82)$ & $1.13(1.37)$ & $1.02(1.24)$ & $1.69(1.93)$ & 0.011 \\
\hline Conduct problems scale, mean (SD) & 1059 & $0.91(1.08)$ & $0.95(1.04)$ & $0.89(1.07)$ & $0.97(1.16)$ & $1.14(1.18)$ & 0.474 \\
\hline Hyperactivity scale, mean (SD) & 1057 & $2.23(1.90)$ & $2.29(2.23)$ & $2.17(1.87)$ & $2.43(1.86)$ & $2.89(1.82)$ & 0.088 \\
\hline Peer problems scale, mean (SD) & 1058 & $0.71(1.24)$ & $0.93(1.24)$ & $0.66(1.18)$ & $0.84(1.51)$ & $1.11(1.43)$ & 0.025 \\
\hline Prosocial scale, mean (SD) & 1057 & $8.64(1.41)$ & $8.80(1.19)$ & $8.63(1.40)$ & $8.69(1.47)$ & $8.36(1.90)$ & 0.44 \\
\hline Total Difficulties Score, mean (SD) & 1056 & $5.02(3.82)$ & $5.63(4.43)$ & $4.84(3.63)$ & $5.26(4.24)$ & $6.83(4.55) \ddagger$ & 0.005 \\
\hline Impact scale, mean (SD) & 1046 & $0.12(0.71)$ & $0.07(0.26)$ & $0.12(0.71)$ & $0.15(0.92)$ & $0.14(0.55)$ & 0.879 \\
\hline $\begin{array}{l}\text { Emotional problems scale } \\
\geq 90 \text {-percentile, } \%\end{array}$ & 1059 & 15.7 & 20.7 & 15.2 & 13.9 & 19.4 & 0.487 \\
\hline $\begin{array}{l}\text { Conduct problems scale } \\
\geq 90 \text {-percentile, \% }\end{array}$ & 1059 & 22.6 & 27.6 & 22.3 & 19.1 & 27.8 & 0.453 \\
\hline Hyperactivity scale $\geq 90$-percentile, $\%$ & 1057 & 11.8 & 12.6 & 11.1 & 13 & 22.2 & 0.226 \\
\hline Peer problem scale $\geq 90$-percentile, $\%$ & 1058 & 22.3 & 27.9 & 20.8 & 24.3 & 36.1 & 0.078 \\
\hline
\end{tabular}

Continued 


\begin{tabular}{|c|c|c|c|c|c|c|c|}
\hline & \multirow[b]{2}{*}{ Valid $n$} & \multirow[b]{2}{*}{$\begin{array}{l}\text { All } \\
(n=1088)\end{array}$} & \multicolumn{4}{|c|}{ Current weight category* } & \multirow[b]{2}{*}{$\begin{array}{l}\text { Overall } p \\
\text { value }\end{array}$} \\
\hline & & & $\begin{array}{l}\text { Underweight } \\
(\mathrm{n}=89)\end{array}$ & $\begin{array}{l}\text { Normal weight } \\
(\mathrm{n}=844)\end{array}$ & $\begin{array}{l}\text { Overweight } \\
(\mathrm{n}=117)\end{array}$ & $\begin{array}{l}\text { Obese } \\
(n=38)\end{array}$ & \\
\hline Prosocial scale $\leq 10$-percentile, $\%$ & 1057 & 19.2 & 12.8 & 19.3 & 21.7 & 25 & 0.316 \\
\hline $\begin{array}{l}\text { Total Difficulties Score } \geq 90 \text {-percentile, } \\
\%\end{array}$ & 1056 & 10.3 & $18.6 \ddagger$ & 8.7 & 11.3 & $25.0 \ddagger$ & 0.001 \\
\hline
\end{tabular}

${ }^{*}$ Based on the age and sex specific BMI criteria by the International Obesity Task Force. ${ }^{2425}$

†P value from comparing all weight groups, that is, from one-way analysis of variance for continuous, and $\chi^{2}$ for categorical variables.

$\ddagger P$ value $\leq 0.05$ in post hoc pairwise comparison with the normal weight group using Dunnett's t-test (continuous variables) and $\chi^{2}$ test (categorical). Only performed when overall $\mathrm{p} \leq 0.05$.

$\S$ Computed from the three dimensions on physical activity: frequency, intensity and endurance, each scored from 1 to 3 (better than peers, like peers, poorer than peers), giving a total score of 3-9, where 9 meant poorer than peers in all three dimensions. The figure is the prevalence of children with a score of 6 or higher.

IAny current or previous chronic illnesses.

${ }^{* *}$ At least three of the following: sweets $>1$ day/week, soft drink $>1$ day/week, fast food $>1$ day/week, breakfast $<4$ days/week, vegetables $<2$ days/ week, fruit $<5$ days/week.

††If the child scored lower than their peers on fine motor, language or social skills, had sleep problems after 2 years of age, or if they had received any professional interventions within physiotherapy, speech therapy, psychology or psychiatry, or had received any extra support in kindergarten after 2 years of age.

$\ddagger \ddagger S y m p t o m$ scores range from 0 to 10 , Total Difficulties Score is the sum of the first four symptom scores (range 0-40). High score in the symptom scores means more problems, except for the Prosocial scale, which is scored opposite. Impact range 0-10.

BMI, body mass index; SDQ, Strength and Difficulties Questionnaire; SDS, SD score ${ }^{23}$.

a theoretical perspective. We adjusted according to two models: In Model 1 we adjusted for the family related covariates, and in Model 2 we added health and lifestyle covariates of the child to the family related covariates (table 2). Associations were described as OR and $95 \%$ CI. The explanatory variables were tested for interactions and multicollinearity. We also explored if TDS90 was associated with BMI SDS in linear spline regression analyses. $^{30}$

We used Stata for the spline analysis and SPSS Statistics for Windows V.25.0 for the other analyses. P values $\leq 0.05$ were considered statistically significant. BMI SDS were calculated using R V.2.6.0 (The R foundation for Statistical Computing, Vienna, Austria) using Norwegian growth references. ${ }^{25}$

\section{RESULTS}

Of 1895 eligible families, 1119 participated, but analyses were limited to $1088(57.4 \%)$ due to incomplete information for 31 children.

There were significant differences between groups on several health-related and sociodemographic factors (table 1A). In the pairwise analyses, low physical activity and family factors such as low parental education, parents being out of work, single parenthood, non-Western ethnicity, mother smoking and OW or OB in parents and siblings were all significantly associated with $\mathrm{OW}$ or $\mathrm{OB}$ in the children. UW was only associated with low weight in other family members (table 1A).

There were significant curvilinear associations between mean scores on the SDQ subscales emotional problems and peer problems and weight category with NW as nadir. Scores on the hyperactivity scale and prosocial scale, but not the impact score, showed similar trends (table 1B). There was a similar tendency for the proportion of children with subscale scores at or above the 90th percentile (table 1B). For the mean TDS and TDS90 the curvilinear association was statistically significant (table 1B).

In the unadjusted logistic regression analyses, TDS90 was significantly associated with weight group (table 2). However, compared with the children with NW, the risk of TDS90 was only significantly higher for children with UW and OB, not OW (table 2). TDS90 was also associated with most of the other family and child related social, health and lifestyle factors, but not with the parents' weight (table 2). When adjusted for family related factors (Model 1), TDS90 was only significantly associated with UW, mother being out of work and behaviour difficulties in the family. When adding child-related variables to the family factors (Model 2), TDS90 was only significantly associated with UW, mother being out of work and skills related to fine motor, language or social function, or sleep behaviour (table 2). Parental weight was not included in the models because missing values reduced the sample size to 806 in Model 1 and 782 in Model 2. However, the results were essentially the same when this variable was included. There were no significant interactions or collinearity between the explanatory variables.

In the multiple linear spline regression with knots dividing the data on BMI SDS into four quartiles, we found a significantly higher, but decreasing risk of TDS90 with increasing BMI SDS within the first quartile $(\mathrm{OR}=0.48$, $95 \%$ CI: 0.26 to 0.87 ), but no changes from the low risk in the second and later quartiles. The results for the other included risk factors did not change substantially.

\section{DISCUSSION}

The broad picture from the unadjusted analyses was that children with UW and OB, but not OW, had more 
Table 2 Logistic regression analyses of associations between Total Difficulties Score $\geq 90$ th percentile (TDS90) on the Strengths and Difficulties Questionnaire (SDQ) and weight category in an unselected regional cohort of 5-year-old children in Oppland County, Norway. Results are presented unadjusted and adjusted for family and child related factors

\begin{tabular}{|c|c|c|c|c|c|c|c|c|c|c|}
\hline \multirow{2}{*}{$\begin{array}{l}\text { Explanatory variable } \\
\text { Category }\end{array}$} & \multicolumn{4}{|c|}{ Unadjusted } & \multicolumn{3}{|c|}{$\begin{array}{l}\text { Adjusted model } 1^{*} \\
(n=950)\end{array}$} & \multicolumn{3}{|c|}{$\begin{array}{l}\text { Adjusted model } 2^{*} \dagger \\
(\mathrm{n}=911)\end{array}$} \\
\hline & $\mathbf{n}$ & OR & $95 \% \mathrm{Cl}$ & $P$ value & OR & $95 \% \mathrm{Cl}$ & $P$ value & OR & $95 \% \mathrm{Cl}$ & $P$ value \\
\hline $\begin{array}{l}\text { Weight group child (NW } \\
\text { reference) }\end{array}$ & 819 & & & 0.002 & & & 0.017 & & & 0.023 \\
\hline UW & 86 & 2.41 & 1.33 to 4.37 & & 2.69 & 1.37 to 5.27 & & 2.87 & 1.41 to 5.85 & \\
\hline OW & 115 & 1.34 & 0.72 to 2.51 & & 1.04 & 0.51 to 2.12 & & 1.18 & 0.57 to 2.45 & \\
\hline OB & 36 & 3.51 & 1.59 to 7.76 & & 2.19 & 0.84 to 5.73 & & 2.02 & 0.73 to 5.62 & \\
\hline Low maternal education & 1037 & 2.23 & 1.47 to 3.39 & $<0.001$ & 1.44 & 0.86 to 2.40 & 0.167 & 1.44 & 0.84 to 2.46 & 0.187 \\
\hline Low paternal education & 1006 & 2.23 & 1.37 to 3.62 & 0.001 & 1.66 & 0.94 to 2.93 & 0.080 & 1.67 & 0.93 to 3.01 & 0.086 \\
\hline Mother out of work & 1037 & 4.15 & 2.44 to 7.07 & $<0.001$ & 3.54 & 1.87 to 6.70 & 0.001 & 3.34 & 1.71 to 6.50 & $<0.001$ \\
\hline Father out of work & 1018 & 2.26 & 1.06 to 4.81 & 0.035 & 1.33 & 0.56 to 3.18 & 0.520 & 1.14 & 0.44 to 3.00 & 0.785 \\
\hline Mother smoking & 1056 & 1.70 & 1.08 to 2.67 & 0.021 & 1.09 & 0.63 to 1.91 & 0.753 & 1.06 & 0.59 to 1.91 & 0.838 \\
\hline Living with one caretaker & 1043 & 1.36 & 0.78 to 2.36 & 0.282 & 0.85 & 0.42 to 1.71 & 0.642 & 0.88 & 0.42 to 1.84 & 0.732 \\
\hline Siblings & 1035 & 0.66 & 0.36 to 1.21 & 0.177 & 0.77 & 0.38 to 1.59 & 0.486 & 0.88 & 0.42 to 1.87 & 0.745 \\
\hline $\begin{array}{l}\text { Behaviour difficulties in the } \\
\text { family }\end{array}$ & 1056 & 2.59 & 1.38 to 4.85 & 0.003 & 1.55 & 0.73 to 3.30 & 0.254 & 1.23 & 0.56 to 2.71 & 0.610 \\
\hline Girl & 1056 & 0.71 & 0.47 to 1.05 & 0.086 & & & & 0.84 & 0.53 to 1.35 & 0.477 \\
\hline $\begin{array}{l}\text { Physical activity score poorer } \\
\text { than for peers }\end{array}$ & 1044 & 2.99 & 1.55 to 5.77 & 0.001 & & & & 2.15 & 0.97 to 4.77 & 0.059 \\
\hline Low nutritional standard & 1040 & 1.48 & 0.86 to 2.55 & 0.158 & & & & 1.22 & 0.64 to 2.35 & 0.550 \\
\hline Dental caries & 1049 & 2.07 & 1.34 to 3.19 & 0.001 & & & & 1.47 & 0.85 to 2.54 & 0.166 \\
\hline $\begin{array}{l}\text { Difficulties in fine motor, } \\
\text { language or social skills, or } \\
\text { sleep }\end{array}$ & 1033 & 3.42 & 2.28 to 5.13 & $<0.001$ & & & & 3.15 & 1.96 to 5.07 & $<0.001$ \\
\hline
\end{tabular}

*Family related covariates: low maternal education, low paternal education, mother out of work, father out of work, mother smoking, living with one caretaker, having siblings and ADHD in the family. Weight group of parents is not included because missing values resulted in lower numbers, but the results were essentially the same when included ( $n=806$ in model 1 and $n=782$ in model 2$)$.

tLifestyle covariates: sex, combined physical activity score poorer than peers, low nutritional standard, dental caries and difficulties in fine motor, language or social skills, or sleep.

ADHD, attention deficit hyperactivity disorder; NW, normal weight; OB, obesity; ${ }^{26} 27 \mathrm{OW}$, overweight; UW, underweight.

psychological problems, expressed as emotional symptoms, peer related problems and TDS90, than children with NW. However, after adjusting for numerous unfavourable family and child related factors, only UW and a BMI SDS similar to UW were independently associated with having psychological problems.

The lack of significant psychological consequences of having OW or OB may be unexpected since such associations are well documented in later life. ${ }^{9-13}$ It may also be unexpected because preschool children are conscious of and often express dissatisfaction with their body size, including a desire for a thinner or larger body shape. ${ }^{31-33}$ However, despite this awareness, most preschool children seem to be satisfied with their appearance. ${ }^{33} 34$ The size may not have a psychological impact at this age because acceptance is largely dependent on the attitudes of the parents. ${ }^{32}$ Furthermore, although anti-OB attitudes may occur as early as at $3-5$ years of age, they do not generally occur in a playmate selection. ${ }^{35}$ The vast majority of our children were in kindergarten from 2 years of age, and we suggest that this social setting over years may have reduced any tendencies to focus on body size. It has also been reported that girls who were followed from 5 to 7 years of age, tended to idealise a larger body size than their own at 5 , but a thinner size at $7 .{ }^{34}$ However, despite a desire to have a different body size, the girls were satisfied with their appearance, even at 8 years of age. ${ }^{34}$ The authors therefore suggested that a desire for a different body size represented a cognitive construct without implying psychological consequences.

Our finding that the occurrence of psychological difficulties did not differ between children with OW and NW in any of the analyses, may not be surprising because we have previously shown that Norwegian children with OW are usually perceived by their parents as having a normal body proportion. ${ }^{36}$ Furthermore, BMI may not be a good measure to differentiate between OW and NW in young children because OW may mainly be due to a high lean body mass. ${ }^{37}$

The finding that UW per se was associated with psychological difficulties has, to our knowledge, not been reported previously for this age group. In later 
childhood, children with UW, which also implies shorter stature and lower muscle mass, were almost as likely to be teased by peers as children with $\mathrm{OB} .{ }^{38}$ Dominance, and even bullying and victimisation, are common phenomenon during preschool years, ${ }^{39}$ and we suggest that the children with UW may suffer from being the weaker or least robust part in a kindergarten setting. Alternatively, that parents' worry for their lean children ${ }^{19}{ }^{20}$ or restrictive attitude to their children's eating behaviour, ${ }^{20}$ may have had a negative influence on the children's mental health. However, we suggest that the latter explanation is less likely since UW, as opposed to $\mathrm{OW}$ and $\mathrm{OB}$, was not associated with sociodemographic or family behavioural factors, but with low weight and length at birth and their parents' BMI which may imply genetic predisposition. ${ }^{21}$

There has been an ongoing debate on the significance of ADHD or other behavioural problems as risk factors for OW and OB. Two meta-analyses concluded that ADHD is a risk factor for adolescent and adult OW and $\mathrm{OB}$, but not ${ }^{15}$ or possibly a minimal risk factor ${ }^{14}$ for childhood OW and OB. Cortese et al did not state the age of included children in their meta-analysis, but from the text it is unlikely that young children were included. ${ }^{14}$ No preschool children were included in the systematic review by Nigg et al. ${ }^{15}$ There was no association between behavioural problems and OW or OB in our study, which is in line with the findings in a large Norwegian cohort who was assessed with The Child behaviour Checklist at 18 and 36 months of age. ${ }^{40}$ In another Norwegian study of children aged 6-12 years, mothers of children with OW and OB rated their children lower on energy, optimism, compliance, concentration, perseverance and selfconfidence, and higher on egocentricity, irritability and anxiety than mothers of children with lower BMIs on the Norwegian Hierarchical Personality Inventory for Children. ${ }^{41}$ These children were older, but we cannot exclude that preschool children with OB may have psychological symptoms that was not detected with the SDQ.

The strengths of the study were the unselected regional setting where we could assume that the participants were reasonably representative of all the eligible children and families, and the extensive information on the families and children who participated. We cannot exclude selection bias since we had no information on social or health issues on families who declined to participate. However, the participation rate varied from $20 \%$ to $85 \%$ in the different municipalities ${ }^{21}$ suggesting that varying motivation by public health nurses to recruit families had a greater impact on the participation rate than potential selection bias. The somewhat limited number of participants with weights other than NW and dependencies on reports by parents on questionnaires rather than professional assessments were other weaknesses.

\section{CONCLUSION}

Our results suggest that the excess occurrence of psychological difficulties in preschool children with OW and
$\mathrm{OB}$ was due to stresses related to family factors rather than their body size. UW and a low BMI was associated with having psychological symptoms, also after adjusting for family-related factors. We suggest that the reason may be that children with UW are the weaker part in a group setting like kindergarten although we cannot exclude that parental concern or restrictive attitudes were of significance.

\section{Author affiliations}

${ }^{1}$ Department of Paediatrics, Sykehuset Innlandet HF Divisjon Lillehammer, Lillehammer, Norway

${ }^{2}$ Clinic of Child and Adolescent Psychiatry, Otta, Sykehuset Innlandet HF Psykisk Helsevern, Brumunddal, Norway

${ }^{3}$ Department of Clincal Science, Universitetet i Bergen Det Medisinske Fakultet, Bergen, Norway

${ }^{4}$ Department of Public Health and Primary Health Care, Universitetet i Bergen Det Medisinske Fakultet, Bergen, Norway

${ }^{5}$ Department of Paediatrics and Adolescent Medicine, Haukeland

Universitetssjukehus, Bergen, Norway

${ }^{6}$ Department of Research, Innlandet Hospital Trust, Brumunddal, Norway

Acknowledgements The authors are indebted to the public health care clinics in Oppland county for their contributions in establishing the project, to all the families who volunteered to participate and to registered nurses Anne Berit K Sundby, Turid Skundberg, Ragnhild Gunstad, Liv Thorsen and Randi Asbjørnsen, physiotherapists Karianne Storesund, Randi Bragelien and Merete Welhaven Steen, nutritionists Kristina W Monsbakken and Eli Nyhagen, occupational therapists Gro Lisbeth Hofstad and Gjertrud Skundberg and paediatrician Halvor Bævre for their invaluable contributions in collecting data and conducting the intervention program.

Contributors HMD contributed to planning, statistical analyses, interpretation of results, and initial drafting and writing of the paper. HT participated in analyses and interpretation and initial drafting and writing of the paper. $\mathrm{JH}$ contributed to conceptualisation and design of the study, collection of data, planning and interpretation of the results. RB contributed to planning, presentation, analyses and interpretation of results. GEE contributed to planning of presentation and statistical analyses, interpretation of results and writing of the paper. PJ contributed to planning, presentation, analyses and interpretation of results and writing of the paper. TM contributed to conceptualisation and design of the study, collection of data, presentation and interpretation of results and writing of the paper. All authors read and approved the final version of the paper.

Funding The study was supported by grants from The South-Eastern Norway Regional Health Authority (Helse Sør Øst) and Innlandet Hospital Trust. Grant number not applicable.

Patient consent for publication Not required.

Ethics approval The study was approved by the Regional Committee on Medical Research Ethics (REK 1.2006.3491) and the Norwegian Data Protection Official for Research (02-2006 SI). A signed consent was obtained from one of the parents.

Provenance and peer review Not commissioned; externally peer reviewed.

Data availability statement Data are available upon reasonable request by contacting the corresponding author.

Supplemental material This content has been supplied by the author(s). It has not been vetted by BMJ Publishing Group Limited (BMJ) and may not have been peer-reviewed. Any opinions or recommendations discussed are solely those of the author(s) and are not endorsed by BMJ. BMJ disclaims all liability and responsibility arising from any reliance placed on the content. Where the content includes any translated material, BMJ does not warrant the accuracy and reliability of the translations (including but not limited to local regulations, clinical guidelines, terminology, drug names and drug dosages), and is not responsible for any error and/or omissions arising from translation and adaptation or otherwise.

Open access This is an open access article distributed in accordance with the Creative Commons Attribution Non Commercial (CC BY-NC 4.0) license, which permits others to distribute, remix, adapt, build upon this work non-commercially, and license their derivative works on different terms, provided the original work is properly cited, appropriate credit is given, any changes made indicated, and the use is non-commercial. See: http://creativecommons.org/licenses/by-nc/4.0/. 
ORCID iD

Trond Markestad http://orcid.org/0000-0002-4725-1769

\section{REFERENCES}

$1 \mathrm{Ng} \mathrm{M}$, Fleming T, Robinson M, et al. Global, regional, and national prevalence of overweight and obesity in children and adults during 1980-2013: a systematic analysis for the global burden of disease study 2013. Lancet 2014;384:766-81.

2 Simmonds M, Llewellyn A, Owen CG, et al. Predicting adult obesity from childhood obesity: a systematic review and meta-analysis. Obes Rev 2016;17:95-107.

3 Donkor HM, Grundt JH, Júlíusson PB, et al. A family-oriented intervention programme to curtail obesity from five years of age had no effect over no intervention. Acta Paediatr 2020;109:1243-51.

4 Loveman E, Al-Khudairy L, Johnson RE, et al. Parent-only interventions for childhood overweight or obesity in children aged 5 to 11 years. Cochrane Database Syst Rev 2015:CD012008.

5 Mead E, Brown T, Rees K, et al. Diet, physical activity and behavioural interventions for the treatment of overweight or obese children from the age of 6 to 11 years. Cochrane Database Syst Rev 2017;24(Suppl 2.

6 O'Connor EA, Evans CV, Burda BU, et al. Screening for obesity and intervention for weight management in children and adolescents: evidence report and systematic review for the US preventive services Task force. JAMA 2017;317:2427-44.

7 Al-Khudairy L, Loveman E, Colquitt JL, et al. Diet, physical activity and behavioural interventions for the treatment of overweight or obese adolescents aged 12 to 17 years. Cochrane Database Syst Rev 2017;32.

8 Luppino FS, de Wit LM, Bouvy PF, et al. Overweight, obesity, and depression: a systematic review and meta-analysis of longitudinal studies. Arch Gen Psychiatry 2010;67:220-9.

9 Griffiths LJ, Parsons TJ, Hill AJ. Self-Esteem and quality of life in obese children and adolescents: a systematic review. Int J Pediatr Obes 2010;5:282-304.

10 Mühlig Y, Antel J, Föcker M, et al. Are bidirectional associations of obesity and depression already apparent in childhood and adolescence as based on high-quality studies? A systematic review. Obes Rev 2016;17:235-49.

11 Sanders RH, Han A, Baker JS, et al. Childhood obesity and its physical and psychological co-morbidities: a systematic review of Australian children and adolescents. Eur J Pediatr 2015;174:715-46.

12 Rankin J, Matthews L, Cobley S, et al. Psychological consequences of childhood obesity: psychiatric comorbidity and prevention. Adolesc Health Med Ther 2016;7:125-46.

13 Sutaria S, Devakumar D, Yasuda SS, et al. Is obesity associated with depression in children? systematic review and meta-analysis. Arch Dis Child 2019;104:64-74.

14 Cortese S, Moreira-Maia CR, St Fleur D, et al. Association between ADHD and obesity: a systematic review and meta-analysis. Am J Psychiatry 2016;173:34-43.

15 Nigg JT, Johnstone JM, Musser ED, et al. Attention-Deficit/ Hyperactivity disorder (ADHD) and being overweight/obesity: new data and meta-analysis. Clin Psychol Rev 2016;43:67-79.

16 Donnchadha S Ó, Bramham J, Greene C. Rethinking the association between overweight/obesity and ADHD in children: a longitudinal and psychosocial perspective. Ir J Psychol Med 2020:1-14

17 Geoffroy M-C, Li L, Power C. Depressive symptoms and body mass index: co-morbidity and direction of association in a British birth cohort followed over 50 years. Psychol Med 2014:44:2641-52.

18 Olsen NJ, Pedersen J, Händel MN, et al. Child behavioural problems and body size among 2-6 year old children predisposed to overweight. results from the "healthy start" study. PLoS One 2013;8:e78974.

19 van Grieken A, Renders CM, Wijtzes Al, et al. Overweight, obesity and underweight is associated with adverse psychosocial and physical health outcomes among 7-year-old children: the 'Be active, eat right' study. PLoS One 2013;8:e67383.
20 Jansen PW, Roza SJ, Jaddoe VW, et al. Children's eating behavior, feeding practices of parents and weight problems in early childhood: results from the population-based generation $\mathrm{R}$ study. Int J Behav Nutr Phys Act 2012:9:130.

21 Donkor HM, Grundt JH, Júlíusson PB, et al. Social and somatic determinants of underweight, overweight and obesity at 5 years of age: a Norwegian regional cohort study. BMJ Open 2017;7:e014548.

22 Goodman R. Psychometric properties of the strengths and difficulties questionnaire. J Am Acad Child Adolesc Psychiatry 2001:40:1337-45.

23 Sanne B, Torsheim T, Heiervang E, et al. The strengths and difficulties questionnaire in the Bergen child study: a conceptually and methodically motivated structural analysis. Psychol Assess 2009;21:352-64.

24 The Norwegian Directorate of Health. Guidelines for the municipalities' preventive work in children (Norwegian). Available: https://www.regjeringen.no/globalassets/upload/hod/ dokumenter20fha/is-1154_2619a.pdf [Accessed 20 May 2020].

25 Júlíusson PB, Roelants M, Nordal E, et al. Growth references for 0-19 year-old Norwegian children for length/height, weight, body mass index and head circumference. Ann Hum Biol 2013;40:220-7.

26 Cole TJ, Bellizzi MC, Flegal KM, et al. Establishing a standard definition for child overweight and obesity worldwide: international survey. BMJ 2000;320:1240-3.

27 Cole TJ, Flegal KM, Nicholls D, et al. Body mass index cut offs to define thinness in children and adolescents: international survey. BMJ 2007;335:194.

28 World Health Organisation. The International classification of adult underweight, overweight and obesity according to BMI, 2020. Available: http://www.euro.who.int/en/health-topics/diseaseprevention/nutrition/a-healthy-lifestyle/body-mass-index-bmi

29 Obel C, Heiervang E, Rodriguez A, et al. The strengths and difficulties questionnaire in the Nordic countries. Eur Child Adolesc Psychiatry 2004;13 Suppl 2:II32-9.

30 Harrel FE. Regression modeling strategy with applications to linear models. logistic and ordinal regression, and survival analysis. Second Edition. Springer, 2015.

31 Paxton SJ, Damiano SR. The development of body image and weight bias in childhood. Adv Child Dev Behav 2017;52:269-98.

32 Tatangelo G, McCabe M, Mellor D, et al. A systematic review of body dissatisfaction and sociocultural messages related to the body among preschool children. Body Image 2016;18:86-95.

33 Damiano SR, Gregg KJ, Spiel EC, et al. Relationships between body size attitudes and body image of 4-year-old boys and girls, and attitudes of their fathers and mothers. J Eat Disord 2015;3:16.

34 Dohnt HK, Tiggemann M. Development of perceived body size and dieting awareness in young girls. Percept Mot Skills 2004;99:790-2.

35 Di Pasquale R, Celsi L. Stigmatization of overweight and obese peers among children. Front Psychol 2017;8:524.

36 Júlíusson PB, Roelants M, Markestad T, et al. Parental perception of overweight and underweight in children and adolescents. Acta Paediatr 2011;100:260-5.

37 Freedman DS, Ogden CL, Berenson GS, et al. Body mass index and body fatness in childhood. Curr Opin Clin Nutr Metab Care 2005;8:618-23.

38 Neumark-Sztainer D, Falkner N, Story M, et al. Weight-teasing among adolescents: correlations with weight status and disordered eating behaviors. Int J Obes Relat Metab Disord 2002;26:123-31.

39 Ilola A-M, Lempinen L, Huttunen J, et al. Bullying and victimisation are common in four-year-old children and are associated with somatic symptoms and conduct and peer problems. Acta Paediatr 2016;105:522-8.

40 Garthus-Niegel S, Hagtvet KA, Vollrath ME. A prospective study of weight development and behavior problems in toddlers: the Norwegian mother and child cohort study. BMC Public Health 2010;10:626.

41 Hampson SE, Vollrath ME, Júlíusson PB. Personality and overweight in 6-12-year-old children. Pediatr Obes 2015;10:e5-7. 